Archives

$21 \mid 1998$

1. Pour une histoire comparée du voeu // 2. Les

Cagots

\title{
Le vœu de stabilité chez les chanoines de prémontré
}

Aline Debert

\section{(2) OpenEdition}

Journals

\section{Édition électronique}

URL : http://journals.openedition.org/ccrh/2509

DOI : $10.4000 /$ ccrh.2509

ISSN : 1760-7906

Éditeur

Centre de recherches historiques - EHESS

Édition imprimée

Date de publication : 1 novembre 1998

ISSN : 0990-9141

Référence électronique

Aline Debert, "Le vœu de stabilité chez les chanoines de prémontré », Les Cahiers du Centre de Recherches Historiques [En ligne], 21 | 1998, mis en ligne le 20 avril 2009, consulté le 19 avril 2019. URL : http://journals.openedition.org/ccrh/2509; DOI : 10.4000/ccrh.2509

Ce document a été généré automatiquement le 19 avril 2019

Article L.111-1 du Code de la propriété intellectuelle. 


\title{
Le vœu de stabilité chez les chanoines de prémontré
}

\author{
Aline Debert
}

1 Plus qu'une synthèse sur le sujet, cette contribution se veut un bilan des questions restées sans réponse à ce jour ou encore insuffisamment approfondies.

\section{Les trois vœux : obéissance, pauvreté, chasteté}

2 Il semblerait que c'est dans l'ordre des chanoines de Prémontré (Aisne), fondé en 1120 par saint Norbert (1080-1134) qu'apparaissent les notions des trois vertus religieuses: obéissance, pauvreté et chasteté.

3 Elles sont mentionnées dans le Sermo SS. P. Norberti, sorte de petit traité spirituel attribué à saint Norbert et édité pour la première fois, avec la Vita B, en 1622 par JeanChrysostome Van Der Sterre, abbé de Saint-Michel d'Anvers' ${ }^{1}$, d'après trois manuscrits aujourd'hui disparus (?) provenant l'un de l'abbaye de Knechstadt, le second d'un monastère de Saxe et le troisième d'une circarie française :

Ambuletis ergo in vias Dei caute, ne morte comprehendamini improvise, promptam

observantes obedientiam voluntariam paupertam et famosam castitatem.

Entrez donc dans cette voie de Dieu et marchez-y avec précaution, de peur que la mort ne vous surprenne à l'improviste: et pour cela, pratiquez une obéissance prompte, la pauvreté volontaire et une chasteté à l'abri de tout soupçon ${ }^{2}$.

4 Il serait certes intéressant de retrouver les sources de Van Der Sterre et de les dater précisément. Néanmoins le R.P. François Petit, O. Praem., estime que le texte, s'il n'est peut-être pas de saint Norbert lui-même, en est contemporain et émane d'un milieu prémontré3.

5 Un peu plus tard, Philippe de Harvengt ( $\$ 1183)$, abbé de Bonne-Espérance, dans sa Vita Augustini ${ }^{4}$, qualifie la communauté d'Hippone comme renommée pour sa «sancta continentia», sa "paupertas voluntaria » et sa "humilis obedientia... ». En outre, l'auteur s'étend plus longuement dans son De institutione clericorum, sur les vertus religieuses, et notamment la pauvreté, la continence et l'obéissance. 
6 Un autre auteur, contemporain du précédent, le continuateur prémontré de la Chronique de Gembloux, écrit vers 1155 à propos de saint Norbert :

Ad voluntariam paupertam et promptam obedientiam eosdem diligenter instituit ${ }^{5}$.

7 Cependant les plus anciennes formules de profession qui nous sont parvenues ne mentionnent pas explicitement les trois vœux sinon l'obéissance et invitent à la conversion des mœurs :

Ego, frater N..., offerens, trado meipsum ecclesie Sancti Dyonisii et promitto conversionem morum meorum et stabilitatem in loco secundum Evangelium Christi et apostolicam institucionem et secundum canonicam regulam beati Augustini. Promitto etiam obedientiam perfectam in Christo domno N..., prefate ecclesie preposito, et successoribus ejus, quos sanior pars congregationis canonice elegerit ${ }^{6}$.

8 Il conviendra de suivre l'évolution de la formule de profession à travers les livres liturgiques de l'Ordre et de cerner précisément quand les trois vœux classiques ont été clairement exprimés. La formule actuelle s'énonce ainsi :

Ego, frater N..., offerens trado meipsum ecclesiae N... et promitto conversionem morum et vitam communionis praecipue in paupertate, coelibatu consecrato et oboedientiam secundum Evangelium Christi et apostolicam institutionem, secundum regulam beati Augustini et constitutiones Ordinis praemonstratensis coram N..., huius ecclesiae praelato, et fratribus ${ }^{7}$.

Moi, frère N..., je m'offre et me livre à l'Église de N... Je promets la conversion de mes moeurs et la vie commune, principalement dans la pauvreté, le célibat consacré, l'obéissance selon l'Évangile du Christ et l'institution apostolique, selon la Règle de saint Augustin et les Constitutions de l'ordre de Prémontré, devant N..., prélat de cette Église, et mes frères ${ }^{8}$.

\section{Le vœu de stabilité}


d'obéissance. Il a cependant connu diverses vicissitudes au sein de l'ordre de Prémontré au gré de différentes tentatives de réforme et de sécession.

La congrégation des Prémontrés d'Espagne. Au $\mathrm{XVI}^{\mathrm{e}}$ siècle, en Espagne, certains voyaient dans la nomination à vie des abbés une des causes principales du relâchement des réguliers. Un mouvement se créa en faveur d'abbés triennaux nommés par le chapitre de la congrégation. Au terme de trois années, l'abbé était nommé dans une autre abbaye et ainsi de suite jusqu'à son incapacité à remplir sa charge ${ }^{13}$. Il restera à étudier de près les statuts de cette congrégation pour voir si elle comporte une législation spéciale à propos du vœu de stabilité car ces nouveaux abbés n'en étaient pas moins profès d'une abbaye particulière.

La congrégation de l'Antique Rigueur de Lorraine. Instituée en 1617, sous l'impulsion notamment de Servais de Lairuelz, la congrégation de Lorraine prône un vœu de stabilité non plus dans une abbaye précise mais au sein de la nouvelle congrégation et supprime in loco de la formule de profession ${ }^{14}$. La Révolution mit un terme définitif à ce mouvement.

De part et d'autre de l'Océan. La Seconde Guerre mondiale et l'établissement de régimes communistes dans les pays d'Europe centrale entrânèrent la suppression d'abbayes prémontrées, entre autres, et la déportation, l'emprisonnement ou l'exil de leurs chanoines ${ }^{15}$.

13 Les prémontrés qui vivaient à Csorna [Hongrie] en 1950 furent déportés dans un camp de concentration. Cependant sept d'entre eux purent gagner les États-Unis d'Amérique et établir en Californie la communauté de Csorna demeurant au prieuré Saint-Michel d'Orange, juridiquement fondé en 1961. Le 5 mai 1975, la nouvelle installation devient un prieuré sui juris. Les prémontrés originaires de Hongrie ainsi que tous ceux qui ont fait profession dans la nouvelle Csorna avant cette date se sont vu offrir le choix soit de rester profès de l'abbaye hongroise (sans obligation cependant d'y retourner en raison des événements politiques mais en en gardant l'obligation morale), soit de devenir profès du nouveau prieuré. Ils ont tous choisi de rester à Orange. Mais si certains avaient opté pour Csorna et n'y étaient pas retournés [maintenant que l'abbaye revit] par obéissance à leur abbé... de Csorna, ils ne pourraient élire l'abbé d'Orange mais par contre ils le devraient pour celui de Csorna en raison du droit de filiation.

Il reste donc encore beaucoup de points à éclaircir sur les vœux religieux des prémontrés.

\section{NOTES}

1. Jean-Chrysostome Van Der Sterre, O. Praem., Vita S. Norberti canonicorum praemonstratensium patriarchae Antverpiae apostoli archiepic. Magdeburg ac totius Germaniae primatis..., Anvers, Michel Bunel, 1622, suite de 36 gravures de Théodore Galle.

2. Traduction de Godefroid Madeleine, O. Praem., in Manuel du Tiers-Ordre de Saint Norbert, $2^{\mathrm{e}}$ éd., Caen, 1887, p. 86-94.

3. Pour les arguments étayant cette hypothèse : François Petit, O. Praem., La Spiritualité des Prémontrés aux XII et XIII siècles, Paris, Vrin, 1947, p. 273-282.

4. Philippe de Harvengt, Vita S. Augustini, PL 203, col. 665 et s. 
5. L. C. Bethmann, MGH Script. VI, 1844, p. 300-74.

6. Munich, codex 17.174 , fol. 8-10, manuscript du milieu du XII ${ }^{\mathrm{e}}$ siècle (1140-1150) provenant de l'abbaye de Scheftlam (Allemagne).

7. Constitutionis ordinis canonicorum regularium praemonstratensium, approuvées par le Chapitre général de Wilten, 1970, révisées et approuvées par le chapitre général de Untermarchtal, 1994 et promulguées le 28 août 1995 ; § 64-65 de l'Ordo professionis religiosae, texte approuvé le 7 mai 1987.

8. Traduction du R.P. Bernard Ardura, O. Praem., Rituel de la profession religieuse dans l'ordre de Prémontré, s.l., s.d.

9. Supra note 1

10. PL 198, col. 479

11. PL 198, col. 496 et s.

12. Supra notes 7 et 8 .

13. Bernard Ardura, O. Praem., Prémontrés, histoire et spiritualité, Saint-Étienne, Publications de l'Université, 1995, p. 199 et s.

14. Ibidem, p. 227 et s.

15. Ibid., p. 503 et s. 